\title{
Ignition conditions and characteristics for distillant fuel under to local conductive heating
}

\author{
Arkadiy Zakharevich ${ }^{1, *}$, Pavel Panchenko ${ }^{1}$, and Yekaterina Panchenko ${ }^{1}$ \\ ${ }^{1}$ National Research Tomsk Polytechnic University, 634050 Tomsk, Russia
}

\begin{abstract}
Describes the methodology and results of experimental studies of ignition of diesel fuel and a cloth impregnated with this fuel by a hot steel particle are outlined. The layer thickness of liquid fuel was changed from $1 \mathrm{~mm}$ to $11 \mathrm{~mm}$. It was established dependence of numerical values of the ignition time delay from the thickness layer of diesel fuel. The revealed ignition mode and the limiting layer thickness for diesel fuel when the ignition is missing. As experimental study of the ignition conditions and characteristics for fabric impregnated with diesel fuel under local conductive heating is reported.
\end{abstract}

\section{Introduction}

Statistics of fires for 2011-2016 [1] shows a tendency to reduction of the number of fires in Russia. According to EMERCOM of Russia, only in 2016 there were 139.7 thousand fires, they caused material damage in the amount of 14.3 billion rubles, 8760 people died and 9909 people suffered injuries of varying severity. This problem is especially serious for the chemical, petrochemical, oil refining and related branches of industry, which are characterized by significant concentrations of combustible substances and the existence of various ignition sources of their own nature [2-5]. In order to implement measures for prevention of explosions and fires, it is necessary to know the conditions and characteristics of the formation of combustible systems capable of exothermic decomposition. The difficulty of analyzing the process of ignition of liquids is due to the joint flow of interconnected processes of different physical nature: evaporation, heat conduction, crystallization, diffusion, convection under the mutual influence of thermal, kinetic and hydrodynamic conditions [6,7]. Therefore, experimental studies of the processes of ignition of a layer of distillate fuels, as well as of a tissue partially or completely impregnated with this fuel by a single hot particle, are relevant in the modern world.

The task of the paper is to study experimentally the effect of the thickness of a layer of diesel fuel and fabric impregnated with this fuel on the characteristics and conditions of inertia of the ignition process by a local energy source.

\footnotetext{
Corresponding author: bet@tpu.ru
} 


\section{Experimental technique}

Experimental studies were carried out at the stand, which basic scheme is given in the work [8]. The source of heating were monolithic steel particles in the form of a disk of a typical size (diameter $d_{\mathrm{p}}=6 \cdot 10^{-3} \mathrm{~m}$ and height $h_{\mathrm{p}}=5 \cdot 10^{-3} \mathrm{~m}$ ). The objects of the study were presented by winter diesel fuel DT-Z-K3-38 and fabric impregnated with this fuel. The experiments were performed at room temperature of $298 \mathrm{~K}$ and relative humidity of 60 $70 \%$. A video recording of the process was carried out with the help of high-speed Phantom v411 camera fitted with "TemaAutomotive" software. There were registered moments of contact "particle - slick of diesel fuel", "particle - damp fabric", "a particle - dry fabric" and the appearance of a flame. After processing of the video frames, the ignition delay times $\left(\tau_{\text {ign }}\right)$ were determined. A series (6-8) of experiments was performed for each case with a fixed initial temperature of the steel particle $\left(T_{\mathrm{p}}\right)$. After that, average values of $\tau_{\text {ign }}$ and the root-mean-square deviations were determined for each constant value of $T_{\mathrm{p}}$. As a result of the analysis of the ignition delay times for the experiments, it was established that variation coefficients has varied from $\pm 4.5 \%$ (at high $T_{\mathrm{p}}$ ) to $\pm 9 \%$ (at relatively low $T_{\mathrm{p}}$ ). The systematic error in measuring of the initial temperature of the particle, estimated by the method $[9,10]$, has not exceeded $2 \%$. Obtained mean-square deviations and coefficients of variation can be considered acceptable for the conducted experiments in regard with the complexity of the mechanism for realizing the process, which is under study.

\section{Results and discussion}

Figure 1 shows the ignition delay time of diesel fuel the dependences on the layer thickness $(h)$ obtained in the experiments.

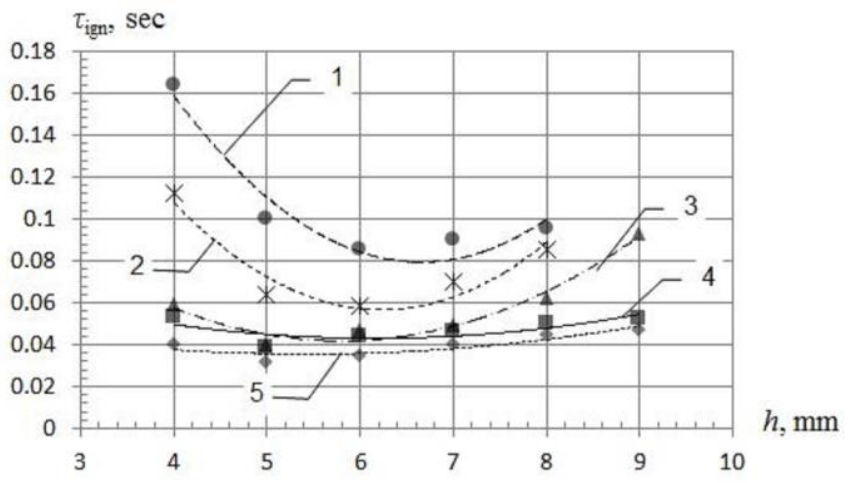

Fig. 1. The experimental dependences of the ignition delay time on the thickness of the diesel fuel layer (h): 1 - a steel particle with a temperature of $1273 \mathrm{~K}, 2$ - a steel particle with a temperature of $1293 \mathrm{~K}, 3$ - a steel particle with a temperature of $1333 \mathrm{~K}, 4$ - a steel particle with a temperature of $1353 \mathrm{~K}, 5$ - a steel particle with a temperature of $1373 \mathrm{~K}$.

The curves correspond to different values of steel particle temperature, which was used as a source of heating (ignition). The minimum and maximum values of the layer thickness correspond to the limiting conditions for initiating the combustion reaction. If the layer thickness is less than $4 \mathrm{~mm}$, when a hot particle falls into a fuel, a dry spot forms. As a result, there is no active evaporation in the immediate vicinity of the heated surfaces of the particle. Consequently, the fuel concentration is insufficient to initiate the fuel ignition process. At sufficiently extreme values of the fuel layer thickness, the particle is completely immersed and there is no ignition. At sufficiently extreme values of the thickness of the fuel layer, the particle is completely immersed. The resulting pairs of diesel fuel are heated 
when the flow around the steel particle. At $\mathrm{h}>9 \mathrm{~mm}$, the energy from the steel particle is insufficient to initiate combustion due to subsequent cooling (when the vapors move upward). Fuel vapours rise up, when the height of vertical channels in the layer is from 4 to $9 \mathrm{~mm}$, and leave out of direct contact with the source of heat energy. As a result fuel vapours shifted toward to particle axis of symmetry and heated by heat exchange with the upper horizontal surface of the particle. In this case the upper surface was source of active heating of diesel vapours. Experimental video analysis shows that ignition reaction proceeds on symmetry axis of system diesel layer - particle - channel filled with fuel vapours.

The resulting pairs of diesel fuel are heated when the flow around the steel particle. At $\mathrm{h}>9 \mathrm{~mm}$, the energy from the steel particle is insufficient to initiate combustion due to subsequent cooling (when the vapors move upward). Fuel vapours rise up, when the height of vertical channels in the layer is from 4 to $9 \mathrm{~mm}$, and leave out of direct contact with the source of heat energy. As a result fuel vapours shifted toward to particle axis of symmetry and heated by heat exchange with the upper horizontal surface of the particle. In this case the upper surface was source of active heating of diesel vapours. Experimental video analysis shows that ignition reaction proceeds on symmetry axis of system diesel layer particle - channel filled with fuel vapours.

From the approximation dependences (Fig. 2), it can be seen that the ignition of the fabric impregnated with fuel occurs at temperatures lower than the films of diesel fuel. This is due to the fact that the fabric has a lower thermal conductivity, which reduces the intensity of heat removal from the steel particle. Consequently, most of the heat is expended directly on the heating and ignition of fuel vapors.

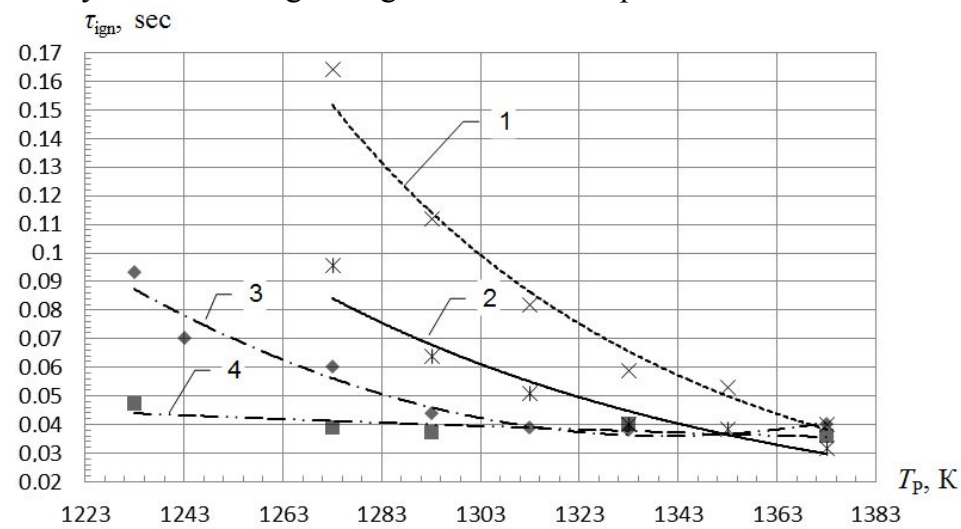

Fig. 2. The experimental dependences of the ignition delay time on the initial temperature of the hot steel particle: 1 - the thickness of the layer of diesel fuel is $4 \mathrm{~mm}, 2$ - the thickness of the layer of diesel fuel is $6 \mathrm{~mm}, 3$ - the fabric is impregnated with fuel with a relative humidity of $85 \%, 4-$ the fabric is impregnated with fuel with a relative humidity of $95 \%$.

On the basis of experimental studies, it is possible to formulate a physical model of the process of ignition of diesel fuel. It is established that ignition of fuel occurs in a small neighborhood of the interface between two media: a steel particle and fuel. Such a mechanism of the ignition process is typical for any layer of the fuel film. Diesel fuel, when interacting with a steel particle, receives heat from it, which is consumed to heat the fuel, namely the phase transition and the heating of the vapors. The resulting vapor, when moving into the oxidant (air) zone, heats up when the particle is flowing around and ignites with a sufficient amount of oxidizing agent. Based on the video recording of the ignition process, the flame appears in the vicinity of the steel particle upper face, having the maximum temperature. 
At a thickness of a layer of fuel more than $9 \mathrm{~mm}$, the steel particle falls in a layer of fuel, exceeding its sizes. There is a complete immersion of the particle. The fuel actively evaporates, and actively removes heat from the particle. To ignite the fuel layer, direct contact of the heated fuel vapors with the heated surface of the steel particle and the amount of oxygen necessary for ignition is necessary. However, with a complete immersion, there are no such conditions, hence there is no possibility of ignition.

If the thickness of the fuel layer is less than $4 \mathrm{~mm}$, then when a hot steel particle falls into fuel, a dry spot forms. As a result, there is no active evaporation (in the immediate vicinity of heated surfaces) and as a result there is no intensive heating of the vapors. As a result, there is no ignition.

\section{Conclusion}

On the basis of experimental studies threshold ignition mode layer of diesel fuel. The obtained experimental dependences of ignition delay time cloth impregnated with diesel fuel from the initial temperature of the steel particles. The significant difference of the inertia of the investigated process ignition "particle fuel", "particle - wet tissue" from the main local source of heating.

The work was supported by the Russian President's grant (Scientific School project 7538.2016.8).

\section{References}

1. M.A. Chebukhanov, A.A. Kozlov, Yu.A. Matyushin, A.G. Firsov, V.I. Sibirko, T.A Chechetin, Fire and fire safety in 2016: Statistical compilation (VNIIPO, Moscow, 2017) [in Russian]

2. M.V. Beschastnov, Industrial explosions. Estimation and prevention (Chimiya, Moscow, 1991)

3. P. Dagaut, M. Cathonnet, Prog. Energy Combust. Sci., 32, 48-92 (2006), DOI: 10.1016/j.pecs.2005.10.003

4. S. Kumagai, Combustion (Khimiya, Moskow, 1979) [in Russian]

5. G.V. Kuznetsov, P.A. Strizhak, J. Eng.Thermophysics 18, 162-167 (2009)

6. V.N. Vilynov, Theory of ignition of condensed substances (Soc. Siberian Branch, Novosibirsk, 1984) [in Russian]

7. D.A. Frank-Kamenetsky, Diffusion and Heat Transfer in Chemical Kinetics (Nauka, Moscow, 1987) [in Russian]

8. A.V. Zakharevich, M.S. Zygin, P.V. Panchenko, Y.A. Vlasova, MATEC Web of Conferences 72, 01128 (2016), DOI: $10.1051 /$ matecconf $/ 20167201128$

9. A.N. Zaidel, Errors of measurements of physical quantities (Nauka, Leningrad, 2009) [in Russian]

10.V.E. Gmurman, The theory of probability and mathematical statistics (Vyssh. Shk., Moscow, 2003) [in Russian] 